\title{
Primary healthcare is cornerstone of universal health coverage
}

\author{
Now we must reinvent primary care to make it happen
}

\author{
Agnes Binagwaho vice chancellor $^{1}$, Tedros Adhanom Ghebreyesus director general ${ }^{2}$ \\ 'University of Global Health Equity, Rwanda; ${ }^{2}$ World Health Organization, Geneva, Switzerland
}

In October 2018, heads of state met in Kazakhstan at the global conference on primary healthcare and renewed their commitment to "health for all" through the Declaration of Astana. ${ }^{1}$ Forty years earlier, the visionary Declaration of Alma-Ata had enshrined primary healthcare as integral to this important goal.

The renewed 2018 commitment to health for all might have been unnecessary if the aims of Alma-Ata had been fully realised. However, primary healthcare has been underfunded globally, particularly in low and middle income countries, ${ }^{2}$ and large health inequalities persist. We must invest more in primary healthcare-and invest more wisely. We must also reinvent primary healthcare to reflect important changes since Alma Ata in 1978.

Firstly, patterns of disease have shifted. Across all countries, the proportion of disability adjusted life years (DALYs) lost to non-communicable diseases grew from $47 \%$ to $60 \%$ between 2000 and $2016 .{ }^{3}$ Primary healthcare has largely failed to keep pace with these changes and requires substantial reform.

Secondly, although Alma-Ata recognised the importance of a multisectoral approach to health, copious research since then has transformed our understanding of the many determinants that interact to shape health outcomes, including housing, education, income, and lifestyle. Traditional configurations of primary healthcare systems lack the flexibility and resources to encompass the social determinants of health.

Thirdly, we now understand more fully the threats facing our species and our planet. We see more clearly that progress in global health is threatened if we fail to tackle issues such as climate change, migration, and conflict. ${ }^{4}$

\section{Sustainable development goals}

In 2016, the sustainable development goals (SDGs) committed countries to fundamental change by 2030, including SDG 3 to "ensure healthy lives and promote wellbeing for all at all ages."

Last year's Astana declaration repositions primary healthcare as the most cost effective, inclusive means of delivering health services to achieve these goals. By placing communities at the centre of healthcare and encouraging participation in design and delivery, primary healthcare can be shaped to match the specific health needs of diverse countries and populations, including the most vulnerable.

Importantly, the declaration asks each country to create an action plan to meet the immediate and longer term primary healthcare needs of its population, to achieve universal health coverage, and to make progress towards the SDGs.

We have already seen, in our own countries, how placing primary healthcare at the heart of all efforts to achieve universal health coverage has transformed population health. In Rwanda, 45000 community health workers serve as the first point of contact for people needing healthcare; they are the functional link between communities and health facilities, such as hospitals. In Ethiopia, tens of thousands of health extension workers bring healthcare to villages and put communities in control of their health. In both countries, primary healthcare has been successfully tailored to local health priorities, as the World Health Organization recommends. ${ }^{3}$

But even more is needed, including investment to modernise healthcare systems and to support the delivery of essential services such as maternal healthcare and vaccinations. Priorities include the development of health information systems fit for new digital technologies and enabled for big data analytics, as well as the capacity to develop, test, and scale up innovations in other areas, including workforce education and systems management.

\section{Integration, collaboration}

This work cannot be done in silos. Governments must integrate their health policies with broader plans for poverty reduction and sustainable development. This requires broad collaboration, including with patients, public and private sectors, and enablers of health service delivery such as innovators in local manufacturing, supply chains, and technology.

Global collaboration is also essential, including efforts by WHO and other leading global health organisations to develop standardised, evidence based tools and resources that support 
the implementation of effective, safe, and patient centred primary healthcare. ${ }^{5}$ With these resources, countries will be able to evaluate progress using internationally comparable datasets that generate robust knowledge about what works, what does not, and why.

It is time to renew our global commitment to Alma Ata's core values and reinvent primary healthcare in a way that accelerates progress towards universal health coverage- safe, effective, and patient centred primary healthcare for everyone. We have the tools and the global leadership to make it happen, and we must seize the opportunity with both hands.

Competing interests: We have read and understood BMJ policy on declaration of interests and have no interests to declare.
Provenance and peer review: Commissioned; not externally peer reviewed.

World Health Organization, United Nations Children's Fund. Declaration of Astana. 2018 https://www.who.int/docs/default-source/primary-health/declaration/gcphc-declaration. pdf.

2 Percent of current government health spending dedicated to PHC. Primary Health Care Performance Initiative; 2017. https://improvingphc.org/indicator/percentage-governmenthealth-spending-allocated-phc\#?loc $=\&$ viz $=0 \&$ ci $=$ false.

3 World Health Organization. Seventy-second World Health Assembly. Report by the Director-General. Universal health coverage. Primary health care towards universal health coverage. Provisional agenda item 11.5 (A72/12), 1 April 2019.

https://apps.who.int/gb/ebwha/pdf_files/WHA72/A72_12-en.pdf

4 Stott R, Smith R, Williams R, Godlee F. Schoolchildren's activism is a lesson for health professionals. BMJ 2019;365:11938. 10.1136/bmj.I1938 31043365

5 Das J, Woskie L, Rajbhandari R, Abbasi K, Jha A. Rethinking assumptions about delivery of healthcare: implications for universal health coverage. BMJ 2018;361:k1716. 10.1136/bmj.k1716 29784870

Published by the BMJ Publishing Group Limited. For permission to use (where not already granted under a licence) please go to http://group.bmj.com/group/rights-licensing/ permissions 